\title{
A Health Behaviour Cross-Sectional Study of Immigrants and Non-immigrants in a Swiss Urban General-Practice Setting
}

\author{
Patrick Bodenmann · Jacques Cornuz Paul Vaucher - William Ghali • \\ Jean-Bernard Daeppen · Bernard Favrat
}

Published online: 30 April 2008

(C) Springer Science+Business Media, LLC 2008

\begin{abstract}
Background Little is known about smoking, unhealthy use of alcohol, and risk behaviours for sexually transmitted diseases (STDs) in immigrants from developed and developing countries. Method We performed a crosssectional study of 400 patients who consulted an academic emergency care centre at a Swiss university hospital. The odds ratios for having one or more risk behaviours were adjusted for age, gender, and education level. Results Immigrants from developing countries were less likely to use alcohol in an unhealthy manner $(\mathrm{OR}=0.35,95 \% \mathrm{CI}$ $0.22-0.57)$ or practise risk behaviours for STDs $(\mathrm{OR}=0.31,95 \%$ CI $0.13-0.74)$. They were also less likely to have any of the three studied risk behaviours $(\mathrm{OR}=2.5,95 \%$ CI 1.5-4.3). Discussion In addition to the usual determinants, health behaviours are also associated with origin; distinguishing between immigrants from developing and developed countries is useful in clinical settings. Surprisingly, patients from developing countries tend to possess several protective characteristics.
\end{abstract}

Keywords Immigration $\cdot$ Health behaviours $\cdot$ Smoking . Unhealthy alcohol use $\cdot$ Sexually transmitted diseases

P. Bodenmann $(\varangle) \cdot$ J. Cornuz $\cdot$ P. Vaucher $\cdot$ B. Favrat Department of Ambulatory Care and Community Medicine, University Outpatient Clinic, Bugnon 44, 1011 Lausanne, Switzerland

e-mail: patrick.bodenmann@hospvd.ch

W. Ghali

Department of Medicine and Public Health,

University of Calgary, Calgary, AB, Canada

J.-B. Daeppen

Alcohol Treatment Centre, University of Lausanne,

Lausanne, Switzerland

\section{Introduction}

Immigrant medical care is a critical issue worldwide. Increasing international migration has raised interest in immigrant health beyond communicable disease [1], and prevention is a key issue for vulnerable immigrant populations [2, 3]. Thus, it is necessary to characterise unhealthy behaviours and risk factors to address the specific prevention needs of those populations $[4,5]$.

In Switzerland [6-8] and other European countries [9], many immigrants are in poor health, and it is clear that immigrants have specific therapeutic and preventative health care needs [9-12], and optimal preventative medical care will target those needs [13]. Little is known about the differences in risk behaviours in immigrant and nonimmigrant patients in European countries, and even less is known about immigrant subgroups from developed and developing countries. Switzerland is a multicultural country situated in the centre of Europe, and it has a diverse immigrant population [14]. A study of ethnic influences on health behaviours of the Swiss population would be ideal. However, defining immigrant groups in clinical settings is difficult [15]. Recent publications have suggested that differentiating immigrants from developed and developing countries would be useful for describing health risk behaviours $[9,12]$. Therefore, our primary objective was to compare the prevalence of unhealthy behaviours in patients of differing origin that consulted emergency care centers [16]. We also evaluated cumulative risks (clustering of risks) across groups, while controlling for known determinants. Finally, we assessed determinants (i.e., gender, age, education level, family situation, occupation, and religion) of smoking, unhealthy drinking, and having risk behaviour(s) for contracting sexually transmitted diseases (STDs) in different immigrant populations. 


\section{Methods}

Participants

Patients attending the emergency care unit at the Department of ambulatory care and community medicine at Lausanne state university hospital, Lausanne, Switzerland, between October 2004 and February 2005 were invited to participate in the study. Informed consent was obtained from all patients after the study protocol had been approved by the University Ethics Committee.

Patients were categorised into three groups. Patients born in Switzerland and with Swiss nationality were considered to be Swiss non-immigrants. The remaining patients were defined as immigrants. The human development index (HDI) [17] was used to further divide the immigrants into immigrants from developed countries (i.e., HDI $\geq 0.8)$ and immigrants from developing countries (i.e., $\mathrm{HDI}<0.8$ ).

\section{Data Collection \& Measures}

Socio-cultural characteristics and background information about general health, smoking habits, alcohol consumption, and sexual behaviour were collected by questionnaire. The questionnaires were written in French, Spanish, English, and Albanian (i.e., the languages most frequently spoken by patients at the hospital).

Questionnaires were completed by patients with the help of a psychologist and a primary care physician. Smoking was considered to be a risk behaviour if a patient smoked at least one cigarette/month. We chose a broad definition of smoking because preventive messages should also be addressed to those who smoke less than one cigarette/day, as they are more likely than non-smokers to become regular consumers and suffer from the same health consequences as regular smokers [18]. We used the Alcohol Use Disorders TestConsumption (AUDIT-C) to assess unhealthy use of alcohol [19]. As suggested by Bush et al. [20], patients with AUDITC scores of $\geq 3$ for females and $\geq 4$ for males were considered to indicate unhealthy use of alcohol. Patients at risk for contracting STDs were those who had not used a condom with an occasional partner or with two partners during the previous 6 months, or used drugs intravenously.

Additional measures, used for descriptive purposes, were the modified Fagerström score, the Prochaska-DiClemente classification, estimated grams of alcohol consumed/day [21], and CAGE score. The questionnaire also included information about patients' integration (i.e., mastery of local language, feeling culturally integrated or feeling stuck between cultures), family situation (i.e., being married or unmarried, having children or not having children), level of education, occupation [22], and the incidence of depression, anxiety, and post-traumatic stress disorder. Information about the circumstances surrounding the patients' visit to the emergency care unit and diseases related to smoking, alcohol consumption or STDs was collected from patient records with their informed consent. Diagnoses were coded by physicians according to an adapted, validated internal index of diagnosis for general practice.

Analysis

The estimated sample size was higher for detecting group differences for smoking than for unhealthy use of alcohol. Based on a previous study [12], we estimated the global rate of smokers to be $30 \%$ and the proportion of immigrant patients to be near 50\% ( $\sim 50 \%$ of those from developing countries). To detect an absolute between-group difference of $20 \%$ in smoking prevalence with a power of $80 \%$ and a significance level of 0.05 , we estimated the necessary sample size to be 399 , which we rounded to 400 .

Swiss natives were considered as the reference group. Differences with immigrants from developed and developing countries were first evaluated using chi-square statistics or Fischer's exact test. The odds of having risk behaviours according to group were adjusted for age, gender, and education using logistic regression. The same model was applied to analyse the association between risks and age, gender, education level, ethnicity, knowledge of local language, length of residence, feelings of integration, religion, and family situation. Independent variables, but not cofactors, in logistic regression were dichotomised. The median age of patients was used as a cut off for age. The classification for education was higher level of education (completion of management school or university) versus lower level of education (incomplete mandatory scholarship, patient's country compulsory school, or apprenticeship). Sample size was calculated with STATA 8.2 (College Station, Texas, USA). SPSS 10.1 (Chicago, Illinois, USA) was used to calculate descriptive statistics, and Statview SAS 5.0.1 (Cary, North Carolina, USA) was used for logistic regression.

\section{Results}

Of 596 patients invited to participate, 400 (72.3\%) completed the questionnaires and were seen by the physician. Reasons of non-eligibility and dropouts are diagramed in a flow chart (Fig. 1).

\section{Patient Characteristics}

Average age of participants was 35.0 years (SD 13.9); a slight majority of men $(218 / 400)$ were represented. The 


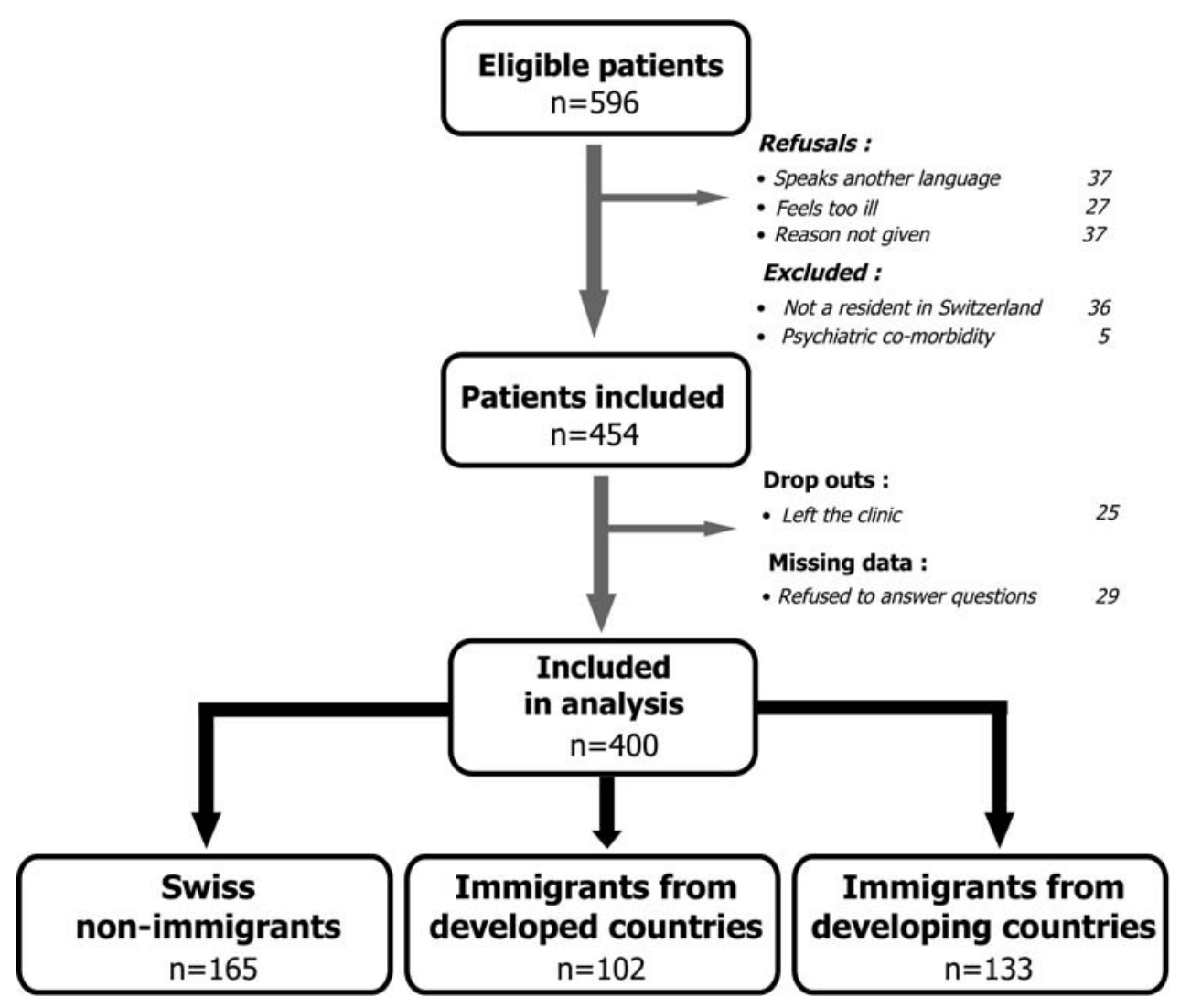

Fig. 1 Flow-chart of patient recruitment

participants were from 65 different countries of origin. The greatest numbers of patients $(41.2 \%)$ were Swiss nonimmigrants. Patients from developed countries were primarily from the European Union (21.5\%), particularly from France $(7.8 \%)$, Portugal (5.5\%), Italy (2.5\%), and Spain (2.3\%). Six (3.4\%) were from European countries outside of the European Union. HDI scores were not available for patients from Serbia-Montenegro, but were expected to be $\geq 0.8$. Ten other patients were from North-, South-, or Central America, including one $(0.3 \%)$ from the United States, two $(0.5 \%)$ from Canada, three $(0.7 \%)$ from Uruguay, two $(0.5 \%)$ from Chile, one $(0.3 \%)$ from Cuba, and one $(0.3 \%)$ from Panama. Patients from developing countries were from sub-Saharan Africa (15.5\%), South America (5.7\%), Eastern Europe (4\%), North Africa (3.5\%), Asia (2.7\%), and the Middle East (1.7\%). Unavailable HDI scores for patients from Kosovo, Afghanistan, Iraq, Somalia, and Liberia were expected to be below $<0.8$.

Patients from developing countries were younger than Swiss non-immigrant patients, and they were likely to be married and Muslim (Table 1). Of the immigrants from developing countries, $12.8 \%$ were not legally eligible to work. Compared to immigrants from developed countries, immigrants from developing countries had a shorter stay in Switzerland, their mastery of the local language was lower, and they were less integrated in the local culture.
Health Status

Patients from the different groups visited the hospital emergency care unit for similar reasons $(P=0.510)$. Compared to Swiss non-immigrants, immigrants from developing countries had fewer health problems related to smoking (28.6\% vs. $46.1 \% ; P=0.003)$. Specific questions to evaluate psychiatric disorders revealed that, compared to non-immigrants, immigrants from developing countries were more likely to be depressed $(35.3 \%$ vs. $21.8 \%$; $P=0.013)$ and anxious (14.3\% vs. $6.1 \% ; P=0.019)$.

\section{Smoking Habits}

The overall prevalence of smokers was of $45.8 \%$ (95\% confidence interval (CI) 40.9-50.6). No between-group differences were observed in patients' levels of addiction $(P=0.552)$ or their will to cease smoking $(P=0.595)$. Male immigrants from developed countries smoked more than male Swiss natives $(64.7 \%$ vs. $42.9 \% ; P=0.015)$ (Table 2).

However, adjusted odds ratios (OR) showed that country of origin was not significantly associated with smoking (Table 3).

After adjustment for age and gender, having a lower level of education $(\mathrm{OR}=2.5 ; 95 \%$ CI $1.6-3.8)$ predicted 
Table 1 Patient characteristics

\begin{tabular}{|c|c|c|c|c|c|}
\hline & \multirow{2}{*}{$\begin{array}{l}\text { Swiss non-immigrants } \\
\text { (Reference group) } \\
(n=165) \\
\%\end{array}$} & \multicolumn{2}{|c|}{$\begin{array}{l}\text { Immigrants from } \\
\text { developed countries } \\
(n=102)\end{array}$} & \multicolumn{2}{|c|}{$\begin{array}{l}\text { Immigrants from } \\
\text { developing countries } \\
(n=133)\end{array}$} \\
\hline & & $\%$ & $P$-Value & $\%$ & $P$-Value \\
\hline Age (years) & & & $0.166^{*}$ & & $0.001 *$ \\
\hline$\leq 20$ & 6.7 & 9.8 & & 7.5 & \\
\hline $21-30$ & 35.2 & 33.3 & & 38.3 & \\
\hline $31-50$ & 37.6 & 39.2 & & 50.4 & \\
\hline $51-65$ & 10.3 & 14.7 & & 3.8 & \\
\hline Over 65 & 10.3 & 2.9 & & 0 & \\
\hline Male & 59.4 & 50.0 & $0.163 * *$ & 51.9 & $0.199 * *$ \\
\hline Female & 50.6 & 50.0 & $0.163 * *$ & 48.1 & $0.199 * *$ \\
\hline Education & & & $0.191 *$ & & $0.064 *$ \\
\hline University & 28.5 & 30.4 & & 26.3 & \\
\hline Management school & 21.2 & 14.7 & & 21.1 & \\
\hline Apprenticeship & 33.9 & 33.3 & & 27.1 & \\
\hline Compulsory school & 15.2 & 15.7 & & 18.0 & \\
\hline Incomplete scholarship & 1.2 & 5.9 & & 7.5 & \\
\hline Married & 27.3 & 38.2 & $0.078 * *$ & 44.4 & $0.002 * *$ \\
\hline Has children & 32.7 & 41.2 & $0.190 * *$ & 43.6 & $0.056 * *$ \\
\hline Religion & & & $0.695^{*}$ & & $<0.001 *$ \\
\hline Christian & 66.7 & 67.6 & & 47.4 & \\
\hline Muslim & 1.8 & 3.9 & & 38.3 & \\
\hline Other & 0.6 & 1.0 & & 3.8 & \\
\hline None & 30.9 & 27.5 & & 10.5 & \\
\hline \multicolumn{6}{|l|}{ Occupation } \\
\hline INSEE classification $^{\mathrm{b}}$ & & & $0.023^{*}$ & & $<0.001 *$ \\
\hline Company director, self-employed businessman & 1.8 & 5.9 & & 1.5 & \\
\hline $\begin{array}{l}\text { Liberal professions, company executive, } \\
\text { professor, engineer }\end{array}$ & 9.7 & 10.8 & & 0 & \\
\hline $\begin{array}{l}\text { Teacher, clerical, social and health employee, } \\
\text { technician, managerial staff }\end{array}$ & 6.7 & 10.8 & & 3.0 & \\
\hline $\begin{array}{l}\text { Security agent, military, administrative employee, } \\
\text { shop assistant }\end{array}$ & 35.2 & 28.4 & & 36.1 & \\
\hline Construction worker & 5.5 & 14.7 & & 15.8 & \\
\hline Retired & 10.9 & 2.9 & & 0 & \\
\hline Student & 18.2 & 12.7 & & 18.0 & \\
\hline Unemployed & 9.7 & 3.9 & & 24.8 & \\
\hline Missing data & 2.4 & 2.9 & & 0.8 & \\
\hline Length of stay in Switzerland & & & $<0.001 * * *$ & & $<0.001 * * *$ \\
\hline$<5$ years & & 20.6 & & 31.6 & \\
\hline $5-9$ years & & 12.7 & & 36.8 & \\
\hline 10-19 years & & 26.5 & & 21.8 & \\
\hline $20-60$ years & & 25.5 & & 7.5 & \\
\hline Born in Switzerland & 100 & 14.7 & & 2.3 & \\
\hline Mastery of local language & & & $<0.001 * * *$ & & $<0.001 * * *$ \\
\hline Low & 0 & 4.9 & & 9.8 & \\
\hline Moderate & 1.2 & 9.8 & & 27.8 & \\
\hline Good & 6.1 & 47.1 & & 45.9 & \\
\hline Mother tongue & $92.7^{\mathrm{a}}$ & 38.2 & & 16.5 & \\
\hline
\end{tabular}


Table 1 continued

\begin{tabular}{|c|c|c|c|c|c|}
\hline & \multirow{2}{*}{$\begin{array}{l}\text { Swiss non-immigrants } \\
\text { (Reference group) } \\
(n=165) \\
\%\end{array}$} & \multicolumn{2}{|c|}{$\begin{array}{l}\text { Immigrants from } \\
\text { developed countries } \\
(n=102)\end{array}$} & \multicolumn{2}{|c|}{$\begin{array}{l}\text { Immigrants from } \\
\text { developing countries } \\
(n=133)\end{array}$} \\
\hline & & $\%$ & $P$-Value & $\%$ & $P$-Value \\
\hline \multicolumn{6}{|l|}{ Feeling of integration } \\
\hline Keeps both cultures separated & & 18.6 & $<0.001 * * *$ & 42.9 & $<0.001 * * *$ \\
\hline Feels stuck between cultures & & 13.7 & $0.005 * * *$ & 29.3 & $0.005 * * *$ \\
\hline
\end{tabular}

smoking habits. Adjusting for gender and level of education, being $<30$ years of age $(\mathrm{OR}=2.3$; 95\% CI 1.5-3.5) also predicted smoking habits. Finally, after adjusting for age, gender and education level, being a construction worker $(\mathrm{OR}=2.1 ; 95 \% \mathrm{CI} 1.1-4.3)$, and being unmarried and not having children $(\mathrm{OR}=2.0 ; 95 \%$ CI $1.3-3.2)$ all predicted smoking habits.

\section{Alcohol Consumption}

Fifty-one percent (95\% CI 46.1-55.9) of the patients were considered to consume alcohol in an unhealthy way. AUDIT-C score differed between groups (Table 2), with immigrants from developing countries having the lowest average score $(2.3 ; 95 \%$ CI 1.9-2.7), followed by immigrants from developed countries $(3.5 ; 95 \%$ CI 3.0-5.0) and Swiss non-immigrants $(3.7 ; 95 \%$ CI 3.3-4.1). Immigrants from developing countries consumed alcohol less frequently $(P<0.001)$, less alcohol per occasion $(P=0.003)$, and had fewer occasions in which they consumed many drinks $(P<0.001)$ compared to Swiss natives. After adjusting for age, gender, and education (Table 3), immigrants from developing countries were less likely to use alcohol in an unhealthy way $(\mathrm{OR}=0.35$; 95\% CI 0.22-0.57). This association remained even when adjusting for religion. Testing for other determinants revealed two significant associations related to cultural origins: immigrants who have mastered the local language and those who had been in Switzerland for $>5$ years were more likely to be unhealthy drinkers $(\mathrm{OR}=1.8 ; 95 \% \mathrm{CI}$ 1.0-3.1 and $\mathrm{OR}=1.6 ; 95 \%$ CI 1.1-2.4, respectively). Other determinants for being at risk for unhealthy use of alcohol were the lack of family support $(\mathrm{OR}=3.8 ; 95 \%$ CI 2.4-6.0), not being Muslim (OR $=2.5$; 95\% CI 1.4$4.5)$, being $\leq 30$ years of age $(\mathrm{OR}=1.7$; $95 \%$ CI $1.1-2.5)$, and being male $(\mathrm{OR}=1.5 ; 95 \% \mathrm{CI} 1.0-2.2)$.
STDs

Overall, $11.5 \%$ (95\% CI 8.7-15.0) of the patients reported practising risk behaviours for STDs. Most patients (327/ $400,81.7 \%$ ) did not have occasional partners. Of those who did, $67.3 \%$ reported they always used condoms. Sixty-five patients $(16.2 \%)$ had more than one partner during the previous 6 months. Of those, $42 \%$ did not use condoms. Table 2 shows the between-group differences of risk behaviours for STDs. After adjustment for age, gender and level of education, immigrants from developing countries were less likely $(\mathrm{OR}=0.31 ; 95 \%$ CI $0.13-0.74)$ to have risk behaviour for STDs compared to Swiss natives (Table 3). Being Muslim was associated with less risk behaviour for STDs $(\mathrm{OR}=5.3 ; 95 \%$ CI 1.2-25), whereas patients $\leq 30$ years of age were more likely have risk behaviours for STDs $(\mathrm{OR}=2.2 ; 95 \%$ CI 1.2-4.2).

\section{Clustering of Risks}

Odds of behaviours compared to Swiss natives are summarised in Fig. 2. Smoking patients were more likely than nonsmokers to use alcohol in an unhealthy way. One-third of the patients $(30.3 \%)$ reported smoking and unhealthy use of alcohol. However, immigrants from developing countries were less likely to smoke or consume alcohol in an unhealthy way $(\mathrm{OR}=0.42 ; 95 \%$ CI 0.26-0.77) and had increased odds of not smoking, using alcohol in an unhealthy way, or practising risk behaviours for STDs (OR $=2.5$; 95\% CI 1.54.3) compared to Swiss natives (Table 3).

\section{Discussion}

The main outcomes of the present study were differences in unhealthy risk behaviours for patients of different origins. 
Table 2 Description of risk behaviours

\begin{tabular}{|c|c|c|c|c|c|}
\hline & \multirow{2}{*}{$\begin{array}{l}\text { Swiss non-immigrants } \\
\text { (Reference group) } \\
n=165 \\
\%\end{array}$} & \multicolumn{2}{|c|}{$\begin{array}{l}\text { Immigrants from } \\
\text { developed countries } \\
n=102\end{array}$} & \multicolumn{2}{|c|}{$\begin{array}{l}\text { Immigrants from } \\
\text { developing countries } \\
n=133\end{array}$} \\
\hline & & $\%$ & $P$-value & $\%$ & $P$-value \\
\hline \multicolumn{6}{|l|}{ Smoking } \\
\hline \multicolumn{6}{|l|}{ Smoking } \\
\hline All & 43.6 & 55.9 & $0.059 * *$ & 40.6 & $0.638 * *$ \\
\hline Males & 42.9 & 64.7 & & 47.8 & \\
\hline Females & 44.8 & 47.1 & & 32.8 & \\
\hline Number of cigarettes per day & & & $0.110^{*}$ & & $0.200^{*}$ \\
\hline$<1$ & 6.7 & 12.7 & & 12.8 & \\
\hline $1-9$ & 8.5 & 7.8 & & 4.5 & \\
\hline $10-19$ & 12.1 & 16.7 & & 9.0 & \\
\hline $20-30$ & 12.1 & 17.6 & & 12.8 & \\
\hline$>30$ & 4.2 & 1.0 & & 1.5 & \\
\hline Delay before first cigarette after awakening & & & $0.024 *$ & & $0.654 *$ \\
\hline$\leq 5 \min$ & 10.9 & 6.9 & & 12.8 & \\
\hline $5-30 \mathrm{~min}$ & 12.1 & 11.8 & & 12.8 & \\
\hline$>30 \mathrm{~min}$ & 20.6 & 37.3 & & 15.0 & \\
\hline \multicolumn{6}{|l|}{ Alcohol use } \\
\hline \multicolumn{6}{|l|}{ Drinks alcohol (during last year) } \\
\hline All & 86.7 & 78.4 & $0.090 * *$ & 66.2 & $<0.001 * *$ \\
\hline Men & 90.8 & 88.2 & & 68.1 & \\
\hline Women & 80.6 & 68.6 & & 64.1 & \\
\hline \multicolumn{6}{|l|}{ Intake } \\
\hline$>40 \mathrm{~g} /$ day alcohol for man and $>20 \mathrm{~g} /$ day for women & 2.4 & 3.9 & $0.486 * *$ & 1.5 & $0.695 * *$ \\
\hline AUDIT-C positive ${ }^{a}$ & 60.0 & 56.9 & $0.701 * *$ & 35.3 & $<0.001 * *$ \\
\hline CAGE positive $\mathrm{b}^{\mathrm{b}}$ & 29.7 & 18.6 & $0.060 * *$ & 15.0 & $0.004 * *$ \\
\hline \multicolumn{6}{|l|}{ Sexual behaviour \& intravenous drug use } \\
\hline \multicolumn{6}{|l|}{ Risk behaviour for STD } \\
\hline All & 14.5 & 13.7 & $1.000 * *$ & 6.0 & $0.023 * *$ \\
\hline Men & 14.3 & 19.6 & & 8.7 & \\
\hline Women & 14.9 & 7.8 & & 3.1 & \\
\hline 2 or more partners during the previous 6 months & 18.2 & 16.7 & $0.869 * *$ & 13.5 & $0.342 * *$ \\
\hline HIV test & 59.4 & 57.8 & $0.898 * *$ & 60.9 & $0.813^{* *}$ \\
\hline \multicolumn{6}{|l|}{ Use of condom } \\
\hline Occasional partner without use of condom & 7.9 & 6.9 & $0.816 * *$ & 3.0 & $0.082 * *$ \\
\hline Multiple partners in the previous 6 months without use of condom & 8.5 & 9.8 & $0.826^{* *}$ & 4.5 & $0.244 * *$ \\
\hline Intravenous drug use & 4.8 & 1.0 & $0.160 * *$ & 0.8 & $0.046 * *$ \\
\hline
\end{tabular}

* $P$-value for chi-square test testing differences with Swiss non-immigrants

** $P$-value for Fisher's exact test comparing to non-immigrants

a AUDIT-C score $\geq 3$ for women and $\geq 4$ or above for men

b CAGE score $\geq 2$

AUDIT-C, Alcohol Use Disorders Test-Consumption; HIV, human immunodeficiency virus

Other determinants of risk behaviour, including level of education, lack of family support, stressful occupations [23], and religion [24] have been described previously.

Switzerland is situated in the centre of migration routes, and is thus affected by migration movements across
Europe. The patients included in the study were from diverse cultural backgrounds. Even if grouping was based on economical rather than ethnic grounds, distinguishing immigrants from developed and developing countries seems appropriate and useful, particularly as it appears to 
Table 3 Odds ratios (OR) for risk behaviours depending on country of origin

\begin{tabular}{|c|c|c|c|c|c|}
\hline & \multirow{2}{*}{$\begin{array}{l}\text { Swiss non- } \\
\text { immigrants } \\
\text { OR }\end{array}$} & \multicolumn{2}{|c|}{$\begin{array}{l}\text { Immigrants from } \\
\text { developed countries }\end{array}$} & \multicolumn{2}{|c|}{$\begin{array}{l}\text { Immigrants from } \\
\text { developing countries }\end{array}$} \\
\hline & & Unadjusted OR & $\begin{array}{l}\text { Adjusted } \mathrm{OR}^{\mathrm{a}} \\
(95 \% \mathrm{CI})\end{array}$ & Unadjusted $\mathrm{OR}^{\mathrm{a}}$ & $\begin{array}{l}\text { Adjusted } \mathrm{OR}^{\mathrm{a}} \\
(95 \% \mathrm{CI})\end{array}$ \\
\hline Smoking & 1.0 & 1.6 & $1.5(0.91-2.6)$ & 0.88 & $0.67(0.41-1.1)$ \\
\hline Unhealthy use of alcohol & 1.0 & 0.88 & $0.9(0.53-1.5)$ & 0.36 & $0.35(0.22-0.57)$ \\
\hline Risks for STD & 1.0 & 0.93 & $0.87(0.42-1.8)$ & 0.38 & $0.31(0.13-0.74)$ \\
\hline Smoking and unhealthy use of alcohol & 1.0 & 1.2 & $1.1(0.66-1.9)$ & 0.53 & $0.42(0.26-0.77)$ \\
\hline $\begin{array}{l}\text { Smoking, unhealthy use of alcohol, } \\
\text { and STD risk behaviour }\end{array}$ & 1.0 & 1.5 & $1.4(0.56-3.5)$ & 0.32 & $0.26(0.07-0.97)$ \\
\hline $\begin{array}{l}\text { No smoking, unhealthy use of alcohol, } \\
\text { or STD risk behaviour }\end{array}$ & 1.0 & 0.78 & $0.81(0.44-1.45)$ & 2.1 & $2.5(1.5-4.3)$ \\
\hline $\begin{array}{l}\text { At least one smoking, unhealthy use of alcohol, } \\
\text { or STD risk behaviour }\end{array}$ & 1.0 & 1.3 & $1.2(0.68-2.2)$ & 0.48 & $0.39(0.23-0.66)$ \\
\hline
\end{tabular}

${ }^{\mathrm{a}}$ OR adjusted for age, gender, and education

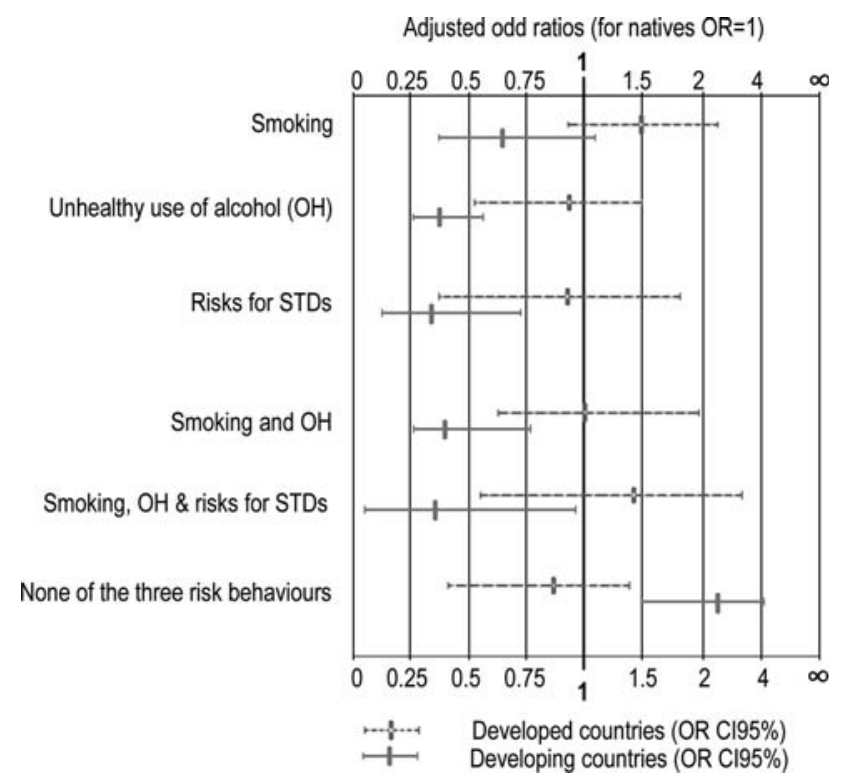

Fig. 2 Odds Ratio (OR) of having risk behaviour(s) compared to natives adjusted for age, gender and education level

be a better determinant of unhealthy risk behaviours than mastery of local language, length of stay in Switzerland, or feelings of integration. Surprisingly, in our study, patients from developing countries were less likely to practice risk behaviours compared to Swiss non-immigrants.

Our study did not reveal any significant association between origin and smoking habits. However, a sub analysis of gender revealed that male immigrants from developed countries were more likely to smoke than Swiss non-immigrants. Similar differences between immigrants from developed and developing countries (not including Turks) were observed in a general survey in The Netherlands [9]. The high prevalence of smoking in male immigrants from developed countries can be explained by the smoking habits of low-wage immigrant workers. Indeed, $47.1 \%$ of that group smoke their first cigarette of the day $>30$ min after waking, a time that they are likely to be at work. This was not the case for immigrants from developing countries. The slight differences in smoking prevalence between gender and origin could also be explained by the smoking habits of one's native country [25]. Immigrants from developed countries smoke more than immigrants from developing countries. This is particularly true for males [12]. Finally the incidence of widespread smoking varies across countries according to the state of their development [26, 27].

Immigrants from developing countries seem to be protected from risk behaviours by a favourable family situation and their cultural background [28]. Being Muslim also seems to have a favourable influence on alcohol consumption [24]. Similar findings were observed for students in Norway [29].

Patient levels of cultural integration did not appear to directly influence risk behaviours. Evidence suggests that behaviours concerning alcohol use may be culturally transmitted by the family to second-generation immigrants [28]. However, Amundsen et al.'s [29] results suggest that the healthy behaviours of immigrants can also favourably influence the behaviours of non-immigrants if the two groups share the same cultural and educational activities. Opinions differ regarding the influence of health behaviours of first- generation immigrants on second-generation immigrants $[9,28,29]$. It may be useful to have more information on the influence of immigration generation on risk behaviours, particularly for immigrants from developed countries. Our observations did not reveal a pattern of drug and alcohol consumption named "killing time" by Dupont et al. [30] by which migrants counter psychological distress. 
Finally, after adjusting for age, gender, and education, immigrants from developing countries were three times less likely to have risk behaviours for STDs. The fact that a majority of patients from developing countries were Muslim and married may explain that finding. Nevertheless, some immigrants with similar or more protective behaviour are at risk for contracting STDs if their native country has high rates of STDs. This is particularly true for immigrants having unprotected sexual relations during visits to their native subSaharan countries [31]. Preventive messages should focus on populations who are at greater risk for STDs. However, immigrants from countries at risk for HIV do not appear to be a risk to the remainder of the population [32].

There is a common association between smoking and drinking [33]. What our study adds is the fact that immigrants from developing countries may be "protected" from risk behaviours for smoking, unhealthy use of alcohol, and contracting STDs. The influence of social gradients on health behaviours are apparently not the same across countries [23, 34, 35]. This indicates the importance of considering the origin of patients to obtain more specific information regarding immigrant needs in terms of preventative medicine.

In the context of European world migration, public health policies should consider specific community needs to address prevention and counselling against risk behaviours for smoking, unhealthy drinking or contracting STDs. Our study supports the fact that preventative messages should target patients who work under stressful conditions, lack family support, and have a low level of education. Efforts should be aimed toward helping immigrants from developing countries to avoid the risk behaviours practiced by other residents of the host country.

\section{Limitations}

This study aims to identify determinants of smoking, unhealthy drinking and sexual behaviours increasing risks of contracting STDs for patients attending a general practitioner for other reasons than receiving advice on these habits. Apparently this population is different to the general population [36] for which our results cannot be generalised. This is likely due to the fact that the population utilising an emergency unit is more at risk of having these risk behaviours [2, 37, 38].

The circumstances under which patients visited the emergency care unit could differentiate them from patients who consult private practitioners. In fact, specific attention to vulnerable populations is characteristic of Lausanne's medical outpatient clinics.

Using HDI index to group patients may not take into consideration cultural characteristics that could influence risk behaviours. Furthermore, cultural habits may change over time. Finally, recall bias could differ between groups.

The response rate of patients was low (72.3\%) but acceptable, as methodological and practical challenges are present when studying vulnerable populations $[39,40]$. The prevalence rate of smoking or unhealthy use of alcohol in patients being close to 0.5 , suggests there would be important discrepancies between calculated prevalence OR and prevalence risk ratios [41]. This limits our ability to compare our results with those that were obtained with different epidemiological measures.

The lack of power in our study, due to small sample size, makes it difficult to exclude existing associations between smoking behaviours and origin. Furthermore, multiple analyses increased the risk of false positive results. Although, the factors we evaluated were based on previous reports, further studies regarding the risk behaviours of immigrants from developed and developing countries are necessary to confirm our results.

\section{New Contribution to the Literature}

Not only are age, gender, education level, and family situation determinants of risk behaviours, but origin and cultural background, such as religion (i.e., Muslim), are also determinant. If we use country of origin as a determinant, it seems sensible to distinguish between developed and developing countries. Actually, country of origin has become a health issue because of new migration policies among the European countries.

Immigrants from developing countries seemed to be protected from risk behaviours. As described by Amundsen et al. [29], healthy behaviours of immigrants may have a positive influence on others in the community. This observation can be useful to help other immigrants and non-immigrants improve their health-related behaviours. Finally, as other studies have suggested [2,3], preventative messages should be privileged in the emergency ward of outpatient clinics, since smoking, unhealthy use of alcohol, and high-risk sexual behaviours are particularly prevalent in that setting.

Acknowledgments We thank Paul Krechtmer, Ph.D., Managing Director of the San Francisco Edit, for reviewing the structure and style of the final draft, Fabrice Althaus, MD, for supervising physicians and managing data during the trial, Marie Pin for enrolling patients and for entering the data, and Christiane Ruffieux, statistician $\mathrm{MD}$, for her participation in statistical planning and analysis. The study received financial support from the Swiss Federal Health Office. They however did not take part in the design, the data collection, analysis, interpretation of the data, the writing of the report or the decision to submit the paper for publication. 


\section{References}

1. Uitewaal PJ, et al. Prevalence of type 2 diabetes mellitus, other cardiovascular risk factors, and cardiovascular disease in Turkish and Moroccan immigrants in North West Europe: a systematic review. Prev Med. 2004;39:1068-76.

2. Sambamoorthi U, McAlpine DD. Racial, ethnic, socio-economic, and access disparities in the use of preventive services among women. Prev Med. 2003;37:475-84.

3. Furler J, Young D. Prevention and socioeconomic disadvantage. Aust Fam Physician. 2005;34:821-4.

4. Gadd M, et al. Do immigrants have an increased prevalence of unhealthy behaviours and risk factors for coronary heart disease? Eur J Cardiovasc Prev Rehabil. 2005;12:535-41.

5. Jacobs DH, et al. Behavioral risk factor and preventive health care practice survey of immigrants in the emergency department. Acad Emerg Med. 2002;9:599-608.

6. Wolff $\mathrm{H}$, et al. Health care and illegality: a survey of undocumented pregnant immigrants in Geneva. Soc Sci Med. 2005;60:2149-54.

7. Bodenmann $\mathrm{P}$, et al. Etre malade et "sans-papiers" à Lausanne: Quo Vadis? Médecine et Hygiène. 2003;61:2023-8.

8. Eytan A, et al. Determinants of postconflict symptoms in Albanian Kosovars. J Nerv Ment Dis. 2004;192:664-71.

9. Reijneveld S. Reported health, lifestyles, and use of health care of first generation immigrants in the Netherlands: do socioecononmic factors explain their adverse position? J Epidemiol Community Health. 1998;52:298-304.

10. Nierkens V, de Vries H, Stronks K. Smoking in immigrants: do socioeconomic gradients follow the pattern expected from the tobacco epidemic? Tob Control. 2006;15:385-91.

11. Brindis $\mathrm{C}$, et al. The associations between status and riskbehavior patterns in Latino-adolescents. J Adolesc Health. 1995;17:99-105.

12. Bodenmann $\mathrm{P}$, et al. Perception of the damaging effects of smoking, and brief cessation counselling by doctors. Swiss Med Wkly. 2005;135:256-62.

13. Wright J. Assessing health needs. In: Pencheon D, et al. editors. Oxford handbook of public health practice. Oxford: Oxford University Press; 2003. p. 38-46.

14. Métraux JC, et al. Les migrants en Suisse. Quand la médecine a besoin d'interprètes. Médecine et Hygiène. Genève: Cahiers Médico-Sociaux; 2003. p. 11-4.

15. Bhopal R. Glossary of terms relating to ethnicity and race: for reflection and debate. $\mathrm{J}$ Epidemiol Community Health. 2004;58:441-5.

16. Santos-Eggimann B. Increasing use of the emergency department in a Swiss hospital: observational study based on measures of the severity of cases. BMJ. 2002;324:1186-7.

17. Watkins K. United Nations Development Program Report. Published for the UNDP; p. 363. http://hdr.undp.org/reports/global/ 2005. Accessed Feb. 2006.

18. Bjartveit K, Tverdal A. Health consequences of smoking 1-4 cigarettes per day. Tob Control. 2005;14:315-20.

19. Saitz R. Unhealthy alcohol use. N Engl J Med. 2005;352:596-607.

20. Bush K, et al. The AUDIT alcohol consumption questions (AUDIT-C). Arch Intern Med. 1998;158:1789-95.

21. Gmel G. The effect of mode of data collection and of nonresponse on reported alcohol consumption: a split-sample study in Switzerland. Addiction 2000;95:123-134.
22. INSEE. Classifications of occupations and socio-occupational categories, PCS 2003. www.insee.fr/en/nom_def_met/nomen clatures/pcs.htm. Accessed Sept. 2006.

23. Borell NL. The role of social class on health behaviors and psychosocial factors: the United States experience. Soz.-Präventivmed. 2005;50:193-94.

24. Ghouri N, Atcha M, Sheik A. Influence of Islam on smoking among Muslims. BMJ. 2006;332:291-94.

25. Tobacco control country profile 2003, http://www.globalink.org/ tccp/. Accessed Feb. 2007.

26. Ramstrom L. Prevalence and other dimensions of smoking in the world. In: Bollinger CT, Fagerstrom KO, editors. The tobacco epidemic. progress in respiratory research. Basel: Karger; 1997. p. 64-67.

27. Wilson CM, Tobin S, Young RC. The exploding worldwide cancer burden: the impact of cancer on women. Int $\mathbf{J}$ Gynecol Cancer. 2004;14:1-11.

28. Dawson AD. Beyond Black, white and Hispanic: race, ethnic origin and drinking patterns in the United States. J Subst Abuse. 1998;10:321-39.

29. Amundsen EJ, Rossow I, Skurtveit S. Drinking patterns among adolescents with immigrant and Norwegian backgrounds: a twoway influence? Addiction 2005;100:1453-63.

30. Dupont HJ, et al. Killing time: drug and alcohol problems among asylum seekers in The Netherlands. Drug Policy. 2004;16:27-36.

31. UNAIDS. 2004 Report on the global AIDS epidemic: 4th global report. Geneva. June 2004. UNAIDS/04.16E.

32. Gras MJ, et al. Determinants of high-risk sexual behavior among immigrant groups in Amsterdam: implications for interventions. J Acquir Immune Defic Syndr. 2001;28:166-72.

33. Shuit AJ, et al. Clustering of lifestyle risk factors in a general adult population. Prev Med. 2002;35:219-24.

34. Williams DR, Collins C. US socioeconomic and racial differences in health: patterns and explanations. Ann Rev Sociol. 1995;21:349-86.

35. De Vogli R, et al. The lack of social gradient of health behaviors and psychosocial factors in Northern Italy. Soz Präventivmed. 2005;50:197-205.

36. Keller R, Krebs H, Hornung R. La consommation de tabac dans la population suisse de 2001 à 2005. Résumé du rapport 2006. Universität Zurich, 2006.

37. Fiellin DA, Reid MC, O'Connor PG. Screening for alcohol problems in primary care: a systematic review. Arch Intern Med. 2000;160:1977-89.

38. D'Onofrio G, et al. Patients with alcohol problems in the emergency department, part 1: improving detection. SAEM Substance Abuse Task Force. Society for Academic Emergency Medicine. Acad Emerg Med. 1998;5:1200-9.

39. Bayoumi AM, Hwang SW. Methodological, practical, and ethical challenges to inner-city health research. J Urban Health Bull NY Acad Med. 2002;79:S35-42.

40. Bischoff A, et al. Language barriers between nurses and asylum seekers: their impact on symptom reporting and referral. Soc Sci Med. 2003;57:503-12.

41. Zochetti C, Consonni D, Bertazzi PA. Relationship between prevalence rate ratios and odds ratios in cross-sectional studies. Int J Epidemiol. 1997;26:220-3. 